\title{
INDONESIAN STUDENTS' STRATEGIES TO COPE WITH FOREIGN LANGUAGE ANXIETY
}

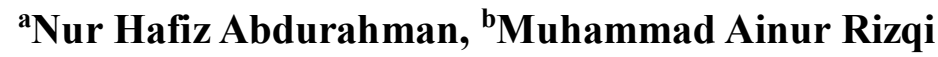 \\ aarahmanhafiz@upi.edu, bainurrizqi89@gmail.com \\ ${ }^{a}$ Universitas Pendidikan Indonesia \\ Jl. Dr. Setiabudi No.229, Isola, Kec. Sukasari, Bandung, West Java, \\ Indonesia 40154 \\ ${ }^{b}$ Universitas Tanjungpura \\ Jl. Prof. Dr. H. Hadari Nawawi, Pontianak Tenggara, Bansir Laut, \\ Pontianak, West Kalimantan, Indonesia 78124
}

\begin{abstract}
Previous research reports that foreign language anxiety (FLA) is one of the affective factors exerting influence on foreign language learning. Myriad studies have examined how foreign language learners cope with foreign language anxiety. However, few studies have addressed the particular moments when students feel the most anxious and how they cope with this anxiety. The present study aims to (1) identify specific moments when students feel the most anxious; (2) investigate their coping strategies, and (3) recognize the changes in the strategies used by the students during specific moments in their language learning. In so doing, a stimulated recall was carried out among five university students from non-English departments who had to conduct presentations in English. The findings show that they displayed different levels of anxiety, which resulted in several accidents during the presentation. The participants with a high anxiety level tended to utilize monotonous coping strategies. This study implies that teachers need to take into account their students' anxiety levels before they commence a new term or semester. When encountering highly anxious students, they can introduce the learners to alternative strategies to cope with anxiety.
\end{abstract}

Keywords: coping strategies, foreign language anxiety, presentation, stimulated recall, university students

DOI: http://dx.doi.org/10.15639/teflinjournal.v31i1/1-18 
Previous research reports that foreign language anxiety (FLA) is one of the affective factors exerting influence upon foreign language learning. FLA, or language anxiety, refers to "a term that encompasses the feeling of worry and negative, fear-related emotions associated with learning or using a language that is not an individual's mother tongue" (MacIntyre \& Gregersen, 2012a, p.103). Several studies have examined how foreign language learners coped with FLA and what implications FLA held beyond classroom contexts (Fallah, 2016; Horwitz et al., 2010; Shao et al., 2013).

During the 1990s, a group of scholars (Sparks \& Ganschow, 1991; Sparks et al., 2000) consistently challenged the language anxiety concept proposed by mainstream experts. Rather than considering language anxiety to be affecting the students' achievement, they believe that it is the students' poor academic attainment that increases the arousal of language anxiety. In other words, it is not language anxiety that determines whether students are successful in learning the second language, but vice versa.

However, other researchers (such as Broidy, 2005; MacIntyre, 1995, 1999; Shao et al., 2013) have shown their objections toward the aforementioned theory. They argue that language anxiety does provide a distraction to the students' attention by presenting task-irrelevant information. When the students are supposed to concentrate only on the new information, the anxious students indeliberately/deliberately divide their focus to think about matters which are unrelated to their language learning. Consequently, this interferes with the learners' language learning and disturbs the flow of information in cognitive processing.

Furthermore, MacIntyre (1999) emphasizes that language anxiety does play a role in the process of language learning by interfering with learners' cognitive processes in input, processing, and output stages. In the input stage, language anxiety could negatively affect their language learning potential and capacity (Shao et al., 2013). For example, anxious students who are overly concerned about negative evaluations tend to have their attention divided. Instead of their receiving information, their attention is also drained as they try to find a solution that reduces people's negative evaluations, which are unrelated to their language task. Therefore, it is not surprising that anxious students tend to show slower performance than those who are more relaxed and able to cope with FLA (Fallah, 2016).

In the processing stage, language anxiety interferes by limiting the students' speed and accuracy in storing information (Horwitz et al., 1986), 
making students less successful than others (Broidy, 2005). Hence, it is difficult for them to learn and remember new vocabulary when they feel anxious in the English classroom. Meanwhile, in the output stage, language anxiety influences the quality of production skills of the language learners. Many studies have shown how the anxious learners quickly become frozen and silent (King, 2013), or simply reluctant to participate in oral activities even when they are capable of doing so and have a chance to speak (MacIntyre, 2007).

Although some scholars agree that anxiety at a tolerable level can be helpful by making the learners stay alert and increase their efforts in learning (Horwitz et al., 1986; MacIntyre, 1995), others believe that high language anxiety correlates negatively with the learners' performance. They posit that anxiety can interfere with language learning processes and have negative effects, for example, on learners' academic achievements (Al-Shboul et al., 2013; Serraj \& Noordin, 2013; Yan \& Horwitz, 2008), social relationships (Liu \& Jackson, 2008; MacIntyre, 2007), personal states (Han, 2013; Huang, 2014; MacIntyre, 1999), and cognitive aspects (MacIntyre, 1995, 1999).

Several studies have also tried to link successfully the ability to cope with FLA with emotional intelligence (Shao et al., 2013), learning process (Mejia, 2014; Trang et al., 2013), language proficiency, social status and competitiveness (Jin et al., 2015), self-esteem and self-coping strategies (Fallah, 2016; Jin et al., 2015), and language test achievement (Cakici, 2016; Kondo \& Ying-Ling, 2004). However, these studies seem unable to describe the dynamic process of students' actual application of coping strategies.

Despite the burgeoning publications on FLA and its coping strategies, the specific literature on the change of strategies that the students experience during one class session is still limited. Thus, the classification of coping strategies in the existing literature can only be interpreted approximately. We can assume that a student only applies one strategy when learning a language. In reality, however, every learner likely deals with different levels of anxiety (Horwitz et al., 2010; Kondo \& Ying-Ling, 2004); hence, they might need different coping strategies.

For this reason, the present study is designed to explore the dynamic process regarding how students actually operate the strategies of coping with their anxiety. First, it aims at identifying specific moments when the students feel most anxious, including the effect that anxiety imposes on the students' performance. Second, it intends to investigate how the students apply the 
coping strategies and recognise the shifts in strategies employed by the students during specific moments in their language learning.

It is important to note that this study attempts to identify the strategies applied by the participants according to Kondo and Ying-Ling's framework (2004); they have pointed to five major basic strategies for coping with FLA: preparation, relaxation, positive thinking, peer seeking, and resignation. In this study, Preparation refers to strategies aimed at compensating for students' low learning skills, for instance, by studying harder or asking questions to teachers or peers. Positive thinking can be defined as strategies to reduce thinking disturbance, such as providing a self-positive statement, or simply praying. Meanwhile, Peer seeking is students' efforts to search for any of their friends who are "in the same boat." This is different from asking for help because, in peer seeking strategies, students attempt to compare their feelings with those of others. Relaxation refers to an effort which aims at lessening self-tension. To do this, the students can touch hair, take a deep breath, and even play with things around them. Finally, Resignation strategies are when students do not make any attempt to alleviate the tension. It is represented by avoiding taking part in the classroom discussion or merely doing nothing in the language class.

\section{METHOD}

\section{Research Design}

This study was conducted using qualitative approach principles, employing a stimulated recall method, which is also recognised as a retrospective method. King (2013, p.131) describes stimulated recall as "a means of investigating individuals' concurrent thinking during specific past events". This is achieved by asking respondents to recall their thought processes straightaway after they have performed specific language learning tasks (McKay, 2009), for example, oral presentations.

Stimulated recall comprises two phases, i.e., observation and interview. Typically, visual or aural aid resulting from the observation is also provided during the interview phase in order to improve the respondent's memory in remembering the original events (Gass \& Mackey, 2000). By having students watch their language performance again, we create a space to obtain a more accurate result. Watching the video or listening to the audio can help them remember the past moments. This activity is important, particularly during an 
interview session, because they are very likely to forget things when encountering unfamiliar environments and persons such as the researchers. Therefore, the video/audio is useful to help them recall their memory in more detail.

Mirzaee \& Hasrati (2014) used stimulated recall method in the second language classroom to help their participants recall the feedback they received more accurately. The method is also prevailing among researchers wishing to investigate students' psychological states. King's (2013) study is about silence behaviours among Japanese students while MacIntyre and Legatto (2011) look at willingness to communicate (WTC). In addition, stimulated recall can be used to identify strategies when students are learning a language (Gass \& Mackey, 2000; Chamot, 2005; McKay, 2009). In this article, the method is directed at uncovering coping strategies used by students when they are dealing with a negative psychological situation such as anxiety. This method may help us understand the reasons behind particular actions performed by the students as they are tasked with giving an oral presentation in the language classroom, for example, regularly scratching the head or smiling exaggeratedly. They are also requested to verbalise unseen actions that they might employ during those moments.

\section{Participants and Recruitment Procedures}

There were five participants in this research who were all English course students from two different classes at a public university in Indonesia. They were aged 18-20, spoke Indonesian as their native language, and studied in engineering (John and Sasha) and teacher training (Jim, Sarah, and Wendy) faculties. To ensure anonymity, all names used in this study are pseudonyms. The course was obligatory for our participants. Both classes had similar language tasks, i.e., to give a presentation after the mid-semester. To enhance students' oral participation, the students were permitted to speak in their first language alternately with English. However, during the presentation, they were instructed to speak in English, although some students occasionally switched to their first language, especially when encountering difficult words.

Non-English-department students were thought to have lower English ability and barely used English in their daily activities; thus they were chosen. The main selection criteria was that they must have been required to perform oral presentations as the primary assessment in the English classroom. The 
reason behind this requirement is that such language tasks can induce a high level of anxiety in the students (see MacIntyre \& Gregersen, 2012b). Therefore, the possibility to feel anxious and nervous during the presentation is higher, and the students are expected to apply certain strategies to ease the negative effects of anxiety.

As this paper is a part of larger-scale research, initially, 69 students were requested to fill in a questionnaire. Then, for the stimulated recall, we chose two students with a high anxiety level, one student at the medium level, and two students who experienced low anxiety to become participants and asked whether they agreed to join in the stimulated recall phase. The difference between students' anxiety levels was ascertained from their self-rated responses in the questionnaire. They were asked to rate their feelings when giving presentations in English from one (1) to five (5), with one being the least anxious and five being the most anxious.

\section{Data Collection}

This study was conducted in three sessions over three weeks where both authors became the observers and interviewers with the help of two English language teachers to teach their respective classes. Week 1 was devoted solely to collecting questionnaire data (11 open-ended questions and 1 Likert scale question). The open-ended questionnaire was adapted from the MacIntyre and Gregersen's (2012b) lists of twelve potentially anxious environments and Zhang and Zhong's (2012) four anxiety categories: learner-induced anxiety, classroom-related anxiety, skill-specific anxiety, and socially-imposed anxiety. Meanwhile, stimulated recall was carried out in Weeks 2 and 3. The authors' presence as foreigners in the classroom is likely to create an observer's paradox, "whereby the presence of a researcher influences subject's linguistic behaviour" (King, 2013, p.9). To minimise this effect, we attended the class several times before the actual data collection to help the students become familiar with our presence.

In Week 2, there was no data taken to the analysis stage. King (2013) suggests this to increase the reliability of the data and to help the students become familiar with the observational situation. Moreover, the observation in Week 2 caused minor revisions to the research protocol, including some questions that we could pose to students during the interview section in the subsequent observation, because we wished to dig into more information 
during the interview. As a result, each video tape was played twice for the students' sharing sessions and during the authors' questioning sessions.

The second observation was conducted in Week 3, which was followed by a face-to-face interview. First, students watched the video that captured the moments during the presentation. Then, they needed to recall their memories by freely pausing and stopping the video fragments themselves. If necessary, the researchers could ask several questions, too. However, we did not pursue students' answers when they did not remember the part, as 'fishing' for forgotten answers might likely yield answers based on the current perception (i.e. incorrect answers). During the interview, the students were advised to speak in their first language, Indonesian, to allow better articulation and expression of feelings and thoughts without having to deal with second language barriers.

\section{Data Analysis}

As this design involved the interview phase, which took around 11-24 minutes for each participant, the audio data were carefully and thoroughly listened to, transcribed, and translated into English. After that, the data was translated again into Indonesian. This multiple translation technique has been used quite frequently in qualitative-based research (e.g. King, 2013; Wei, 2013) to enhance the precision of the translation.

Brown (2001) recommends that qualitative researchers apply interrater reliability to increase reliability. Similarly, we conducted interrater reliability by having each of us code the answers from respondents into several themes. Specifically, in this study, the themes where both researchers were in consensus were moments when students feel nervous and the anxiety coping strategies that they used. Points of difference were removed from the final categorization.

\section{FINDINGS AND DISCUSSIONS}

In this section, rather than merely presenting the thematic results, it seems more beneficial to first hear the whole story of each student separately (a whole person approach), which allows us to identify more personal and unique experiences of students from which a lesson can be harvested. Afterward, the discussions will proceed according to the aforementioned themes to get better 
overviews of students' anxiety moments and anxiety coping strategies as well as to achieve the research purposes stated earlier.

\section{Jim}

When this research was undertaken, Jim was studying in a teacher training faculty. He rated his level of anxiety at 3 , medium. When he was asked to watch his performance and to give comments on it, he explained his difficulties in following the planned outline when giving a presentation in English. This happened especially in the early episodes of his presentation. Jim conveyed that he had prepared everything before the day of his performance, including arranging the sentence orders. Unfortunately, when the day came, he suddenly forgot and skipped that part. He uttered: "erm, at home, I already prepared some words for this part (pointing at the screen), but it was not spoken out. $(0: 04 ': 40$ ")". During his presentation, he admitted that he felt very nervous, and then he looked down. He tried to stay calm. He pretended to look at his hands to mask his anxiety. He avoided looking at his friends for a moment until he felt quite sure about going on with the presentation. He also occasionally gave a smile to reduce the tension.

As the presentation went on, another minor incident occurred. Because Jim felt nervous, he was rushing with the presentation and accidentally dropped a plastic bottle. Jim laughed as he watched this segment in the video. He said that he was surprised. He felt awful, and to divert the other students' attention, he decided to make a joke. He patted on his friend's shoulder. He tried to make his classmates laugh so that they would forget his mistakes.

\section{John}

Based on both his report and the video tape, John appeared as the least anxious student among the other participants. He rated his anxiety level at 2 . During the interview session, he showed a highly enthusiastic manner. Nevertheless, he still experienced a certain degree of anxiety on some occasions. For example, he admitted that some technical problems occurring during his presentation bothered him. According to him, at that moment, he felt confused, blank, and nervous. This sounds similar to the signs articulated by previous students. The possible difference was that John employed various physically active strategies to overcome his anxiety. 
The following anxious moment illustrates some strategies that John used when he forgot the structure of his presentation. As he commented:

“...you can't act awkwardly; the hands should not be put in the pocket, right. So, if I gave a presentation, to overcome the nervousness, I tried to act more like (a) confident guy and I tried to explain something with my hands... haa body language. That's why I used my body (languages) in all the presentation [unclear word] this one this one (pointing at the video). If you see the whole video I used my hands a lot, just like this this (0:07':23")".

Although he looked very confident, he also admitted that the very beginning of his presentation was very suppressing. He became very selfconscious. He doubted if he had spoken correctly or selected the appropriate word and was worried about it. He then decided to make many movements. He walked around, touched his hair, and moved his hands.

\section{Sarah}

Sarah also appeared to experience similar problems. When she watched the video, Sarah commented on a problem she encountered, in which she kept forgetting some sentences as well as the structure of her presentation. When asked about how she managed to continue with the presentation, she highlighted the significance of having some preparation to reduce anxiety. This was primarily to anticipate unexpected events that could happen on the presentation day. Sarah explained, "Important. It is because when we give a presentation, we can't be sure that the media is working a hundred per cent. If (we are) using a projector, it is off whereas we already prepare for the powerpoint slides, and then the projector doesn't work. So it is important to prepare at home. Usually, I do that (0:05':33")".

Furthermore, Sarah also seemed to exhibit a more optimistic attitude. For instance, there was a moment when a model board was falling. She kept telling herself to stay positive. She explained, "it seemed like I always reminded myself to stay positive and give my best because I wanted to have a good mark $\left(0: 08^{\prime}: 25^{\prime \prime}\right)$ '. Further, she also added that she looked at her close friend at the moment after she dropped the board. "hmm, I looked at my close friend's face, at the front row, just looking (at her) ... it gave me power, my close friend, she knew me (0:08':39')"'. 
As observed from the observation session, there were some other strategies that Sarah carried out to mask her nervousness, for instance, by fixing the scarf covering her head. She somehow just kept silent and looked down. She explained that she just needed more time to recall the parts that she forgot in the presentation. At other times, she used things around her and pretended to hold something. Sarah nominated herself to be the first to give the presentation because she wanted to 'lift the burden' quickly. She said "if I haven't given the presentation I feel like freezing (nervous). So, if I go first, I'll feel more relaxed (0:13':39')".

\section{Sasha}

Sasha was enrolled as an engineering student. Looking at her performance, she appeared to experience a higher degree of anxiety during the presentation in comparison to the other participants. Having watched the video, Sasha commented that some technical errors became the primary source of her anxiety, for example, corrupted files or opening the wrong slides.

When asked to share her strategies for coping with this situation, Sasha indicated having adopted 'resignation strategies' (Kondo \& Ying-Ling, 2004). She said, “.. in order to get back normal, I just let it go, ha aa (0:05':05")". However, when she was in the situation where the pictures could not be opened, she commented, "yeah I felt nervous, I got worried of course about how it was going, right? But yeah, it's okay just go ahead (0:07':41")". From the excerpts, Sasha indicated that she made fewer efforts to reduce anxiety. She tended to accept the situation.

In addition to this, Sasha also admitted that she frequently looked at the screen. She barely looked at the audience. She explained:

"...when I gave the presentation, the situation was that I was supposed to look at the audience, right? But, at that time, during the presentation, because I was too nervous, I only looked at the screen...this is to overcome ... if for example there is a classmate who makes a laugh so I do not see him, and overcome my nervousness $\left(0: 13^{\prime}: 25^{\prime \prime}\right)$ '.

Sasha worried that if she looked at her friends who were laughing on the back row, she would lose her focus and that she would forget what she was trying to say. 
Abdurrahman \& Rizqi, Strategies to Cope with FLA 11

\section{Wendy}

Wendy was also a participant in the teacher training faculty. However, unlike her two peers above, she appeared more anxious about her performance. She rated her level of anxiety at 4 . Her high anxiety level was also revealed during the interview session, which only lasted for 11 minutes and comprised of her short answers. As a comparison, the other participants spent approximately 20 minutes in the interview session.

Since the beginning, Wendy was unconfident about presenting her work. Because there was no other student who would voluntarily give a presentation, the students were selected randomly. Wendy was chosen at the time. In response to this, she said, laughing,“ actually, I was not ready. I didn't want to go first. But, I thought it had been decided. So, whether I liked it or not, I had to go ahead. So, I had no preparation (0:02':18")". Indeed, at first, she tried to say 'no' to the decision, but in the end, she decided to go ahead. She apologised for not having been ready. The video showed that she had brought the props that she would use for the presentation. When asked about this, she replied, "Yeah, I did. But, hmm, yeah I already made (the props) but I was not sure what to say for my presentation (0:02':38')". As a result of her nervousness, she could not even look at her classmates, as she thought it would make her even more anxious.

As part of this interview, Wendy was requested to share her strategies for overcoming this stressful situation. She said with a laugh, "Hmm, there was a moment when I look at the notes, yeah, so, I read the text. If I didn't look at the notes, I wasn't able to do it. It would go blank! (0:03':33")" Interestingly, when we looked at the part in the video in which her friends were laughing at her, she applied the same strategy. She decided to divert her eyes. She pretended to look at the notes. Again, at the moment when she forgot some words, she also read the text. In other words, she seemed to apply the same strategy most of the time, regardless of the sources which triggered her anxiety.

\section{Moments when Students Feel Anxious during the Oral Presentation}

The results of the interviews indicate that some moments in the presentation seemed to trigger higher anxiety than the others. More specifically, some students (e.g., John) reported having felt anxious at the beginning of the presentation. Although Jim did not verbalise this explicitly, he appeared to have made more mistakes in the first two minutes during the presentation, which 
indicated that he was experiencing a certain degree of anxiety during these moments. On the other hand, Wendy admitted that being selected randomly to give a presentation was very stressful for her. Some students also reported that their hearts beat faster when they made mistakes or when they simply thought that they would do so during the presentation (Sarah and Jim).

Having observed these moments, it is interesting to discover what was really happening while the students were going through the situations. As an example, the analysis indicated that nearly all students experienced a kind of short-term forgetfulness. As mentioned in the literature review, language anxiety could interfere with the learner's cognitive system in three stages: input, processing, and output (MacIntyre, 1995). Within the processing system, anxiety plays a part in lowering the learner's memory capability so that it confines the short- and long-term memory. As a consequence, it is quite usual to find students who suddenly become forgetful and struggle to remember during language learning (MacIntyre, 1995; Horwitz et al., 1986).

In this study, although the students seemed to have prepared well at home, as soon as they were in front of the class, they suddenly could not remember or skipped some parts of what they had already planned to say. One of the possible reasons was that being anxious hindered them from concentrating and recalling their preparation. They also needed to pay attention to some unrelated information besides memorising sentences for the presentation. For example, they had to think about how to act properly, avoiding their classmates' laughter. Either way, the pressure that they received during the on-going presentation might be very demanding. Therefore, they needed to think of ways to reduce the tension as well as to keep up with the presentation concurrently.

In addition, it is highly likely that an anxious environment triggered students to experience unwanted incidents, for example, careless actions. Jim and Sarah shared stories about their hearts racing as they dropped the presentation props due to their tense feelings. Their classmates' behaviours also seemed to have an impact on the participants' performance, as experienced by Sasha. In the case of Sasha, her classmates' behaviours had caused her to make even more mistakes and to act rather recklessly.

\section{Patterns of How Students Apply Coping Strategies}

Faced with these facts, students in this study indicated having applied various strategies to cope with their anxiety. Preparation strategies were 
perhaps the very beginning strategies that the students used. They applied the strategies before the presentation, which might mean hours or days before. As revealed in the interviews, students who suffered 'forgetful syndrome' during the presentation admitted that they actually had made adequate preparation at home. Individuals who are giving a presentation in their second language usually realize their limited expressive vocabulary, compared to their native language, which may heighten their anxiety. Thus, to compensate for the weakness, the students in this study usually added extra efforts, for example, by studying harder. Adding extra preparation is useful, as Mejia (2014) argues, and may have a positive influence on the students' self-confidence. It is expected to help them gain a better overview before dealing with the actual presentation.

Nevertheless, the interviews also showed that having proper preparation did not seem to guarantee that the students would do well during the presentation day. Some students remained nervous, triggering them to make mistakes. At this point, the pattern was changing. If the students still felt anxious despite adequate preparation for the presentation, more relaxation strategies were employed by the students. They appeared to choose strategies which directly targeted the centre of the anxiety. Thus, the anxiety-healing process is expected to be faster. The students tried to stay calm, pretending to look at the hands, moving parts of the body (John), or looking at their close friends for support. According to Sarah, looking at her close friend could give her more internal power to face the problem.

Besides relaxation strategies, positive thinking strategies were also found to be used as an anxiety reduction method in the middle of the presentation. Sarah, for example, believed that in order to obtain a good mark, she needed to be all out. Thus, she kept telling herself to do the best, although she made careless actions, such as dropping the props. Similarly, when making a mistake, John also did not take it seriously. He tried to assume that it was not a big problem worth worrying about. For some students, positive thinking seems a good way of raising their confidence. This was especially true when they made nerve-wracking mistakes. They did not want to either regret or overthink the mistakes they had made, as they thought it would only make their performance weaker. Therefore, they needed to change the negative feeling by suggesting to themselves positive self-talks. These findings are in line with Fallah's study (2016), which found that students with lower FLA tended to show better coping skills. 
Of the strategies mentioned above, the use of preparation strategies draws our special attention. It can be noticed that preparation strategies employed by the students in this study are limited to sufficient practices or to studying harder before the presentation. Kondo and Ying-Ling (2004) highlight that the presentation strategy is useful to compensate for the student's lack of language skills. In other words, helping students to optimise this kind of strategy is expected to help them perform a better language task. Accordingly, students may feel calmer and less anxious. The teacher can play a role in introducing more strategies, for example, by equipping the students during the presentation with small notes, which they can look at once they forget some parts of the presentation.

Another interesting pattern from the interview is the fact that there seems to be a difference in anxiety-coping strategies between students of lower and higher anxiety levels. Kondo and Ying-Ling's (2004) and Fallah's (2016) studies suggest that both low- and high- anxiety students demonstrated the adoption of different coping strategies. Unfortunately, this does not seem congruent with the results of the stimulated recall data in this study. The difference is indicated by the number of strategies applied by these two different groups. Students who rated their anxiety level at 2 (low anxiety) would have an extensive repertoire of coping strategies. In contrast, highly anxious students seem to have less of a variety of strategies when dealing with anxious moments. Students with a high anxiety level also seem to have monotonous strategies. Sasha and Wendy, who were highly anxious, tended to apply their strategies uniformly across all situations. Additionally, the chosen strategies mostly refer to resignation strategies. Sasha, for instance, preferred to accept the situation rather than making more efforts to be resilient. Even though they applied other strategies, their chosen strategies can be categorized as avoidance strategies as they avoided eye contacts with their classmates during presentations or simply looked at the computer screen in front of them to hide their nervousness. Therefore, we doubt these strategies would provide a significant influence to reduce language anxiety.

\section{CONCLUSIONS}

Stimulated recall data in this study provide a clearer picture of how anxiety-coping strategies are applied in a foreign language classroom. It provides evidence that preparation strategies are mainly used before 
presentations begin. Once the presentation starts and the students are still nervous, they seem to shift the strategies into relaxation or positive thinking strategies, which are capable of diverting their nervousness quickly. Interestingly, this research finds that the use of preparation strategies remains limited to study or practise before the presentation. It could be extended to asking for assistance from peers/teachers or bringing a small note to perform a better presentation.

It is also worth mentioning that there is a difference regarding how less anxious and highly anxious students operate the strategies. The findings suggest that highly anxious students tend to operate resignation strategies, and they are usually monotonous. There is, therefore, a need for teachers to measure the anxiety level of their students before they commence a new term or semester. To do so, the teachers can also utilise social media, which are increasingly prevalent among students (Abdurahman et al., 2018). If the teachers encounter highly anxious students, they can introduce the learners to alternative strategies to cope with anxiety, such as practising uploading their video in Web 2.0 tools such as Edmodo, Google Classroom, YouTube, or other social media.

This research entails some limitations, and, for that reason, recommendations are presented for researchers who are interested in conducting a similar study in the future. First, there is the limitation of students' self-rated anxiety level division in the research. Future researchers can further investigate the level of students' language anxiety using a more reliable scale, such as FLCAS (Horwitz et al., 1986; Trang et al., 2013).

Finally, even though the students document a wide range of strategies, its effectiveness in reducing anxiety remains to be further explored. On a broader scale, there is still little evidence regarding the success of specific strategies in reducing language anxiety. Thus, this study suggests conducting further empirical research that evaluates the success rate of the strategies applied by the students.

\section{ACKNOWLEDGEMENTS}

We would like to thank the Indonesia Endowment Fund for Education (LPDP) for fully funding our study at Leicester University. As a part of the scholarship, LPDP also financially supported the completion of this article. We 
also would like to thank Cary Chapell from Kansas State University, USA for his invaluable feedback that greatly improved this manuscript.

\section{REFERENCES}

Abdurahman, N. H., Gandana, I. S. S., \& Novianti, N. (2018). The fever of English 2.0 in Indonesia: University students' and faculty members' attitudes towards English in different multilingual landscapes. Indonesian Journal of Applied Linguistics, 8(2), 482-488.

Al-Shboul, M. M., Ahmad, I. S., Nordin, M. S., \& Rahman, Z. A. (2013). Foreign language anxiety and achievement: Systematic review. International Journal of English Linguistics, 3(2), 32-45.

Broidy, M. (2005). Emotional intelligence: Personality, gender and cultural factors. (Doctoral dissertation, Fairleigh Dickinson University, Teaneck, New Jersey, USA). Retrieved from https://search.proquest.com/openview/ 17abbbcee39a2b92e47255427682984b/1?pqorigsite $=$ gscholar $\& \mathrm{cbl}=18750 \&$ diss $=\mathrm{y}$

Brown, J. D. (2001). Using surveys in language programs. Cambridge University Press.

Cakici, D. (2016). The correlation among EFL learners' test anxiety, foreign language anxiety and language achievement. English Language Teaching, 9(8), 190-203.

Chamot, A. U. (2005). Language learning strategy instruction: Current issues and research. Annual Review of Applied Linguistics, 25, 112-130.

Fallah, N. (2016). Mindfulness, coping self-efficacy and foreign language anxiety: A mediation analysis. Educational Psychology, 37(6), 745-756.

Gass, S. M. \& Mackey, A. (2000) Stimulated recall methodology in Applied Linguistics and L2 research. Routledge.

Han, L. (2013). Foreign language anxiety: Past and future. Chinese Journal of Applied Linguistics, 36(4), 442-464.

Horwitz, E. K., Horwitz, M. B., \& Cope, J. (1986). Foreign language classroom anxiety. The Modern Language Journal, 70(2), 125-132.

Horwitz, E. K., Tallon, M., \& Luo, H. (2010). Foreign language anxiety. In J. C. Cassady (Ed.), Anxiety in schools: The causes, consequences, and solutions for academic anxieties (pp. 95-118). Peter Lang.

Huang, Y. (2014). Self and language anxiety. English Language and Literature Studies, 4(2), 66-77. 
Jin, Y., de Bot, K., \& Keijzer, M. (2015). Factors associated with foreign language anxiety: A study of Chinese university learners of Japanese and English. Dutch Journal of Applied Linguistics, 4(1), 67-85.

King, J. (2013) Silence in the second language classroom. Palgrave Macmillan.

Kondo, D. S. \& Ying-Ling, Y. (2004). Strategies for coping with language anxiety: The case of students of English in Japan. ELT Journal, 58(3), 258-265.

Liu, M. \& Jackson, J. (2008). An exploration of Chinese EFL learners' unwillingness to communicate and foreign language anxiety. The Modern Language Journal, 92(1), 71-86.

MacIntyre, P. D. (1995). How does anxiety affect second language learning? A reply to Sparks and Ganschow. The Modern Language Journal, 79(1), 9099.

MacIntyre, P. (1999). Language anxiety: A review of the research for language teachers. In D. J. Young (Ed.), Affect in foreign language and second language learning (pp. 24-46). McGraw-Hill.

MacIntyre, P. D. (2007). Willingness to communicate in the second language: Understanding the decision to speak as a volitional process. The Modern Language Journal, 91(4), 564-576.

MacIntyre, P. \& Gregersen, T. (2012a). Affect: The role of language anxiety and other emotions in language learning. In S. Mercer., S, Ryan., \& M. Williams (Eds.), Psychology for language learning: Insights from research, theory and practice (pp. 103-118). Palgrave Macmillan.

MacIntyre, P. \& Gregersen, T. (2012b). Emotions that facilitate language learning: The positive-broadening power of the imagination. Studies in Second Language Learning and Teaching, 2(2), 193-213.

MacIntyre, P. D. \& Legatto, J. J. (2011). A dynamic system approach to willingness to communicate: Developing an idiodynamic method to capture rapidly changing affect. Applied Linguistics, 32(2), 149-171.

McKay, S. L. (2009). Introspective techniques. In J. Heigham \& R.A. Croker (Eds.), Qualitative research in applied linguistics (pp. 220-241). Basingstoke: Palgrave Macmillan.

Mejia, G. (2014). A case study of anxiety in the Spanish classroom in Australia, Journal of University Teaching and Learning Practice, 11(3), 1-13.

Mirzaee, A. \& Hasrati, M. (2014). The role of written formative feedback in inducing non-formal learning among masters students. Teaching in Higher Education, 19(5), pp. 555-564. 
Serraj, S., \& Noordin, N. (2013). Relationship among Iranian EFL students' foreign language anxiety, foreign language listening anxiety and their listening comprehension. English Language Teaching, 6(5), 1-12.

Shao, K., Ji, Z. \& Yu, W. (2013). An exploration of Chinese EFL students' emotional intelligence and foreign language anxiety. The Modern Language Journal, 97(4), 917-929.

Sparks, R. L. \& Ganschow, L. (1991). Foreign language learning differences: Affective or native language aptitude differences? The Modern Language Journal, 75(1), 3-16.

Sparks, R. L., Ganschow, L. \& Javorsky, J. (2000). Déjà vu all over again: A response to Saito, Horwitz, and Garza. The Modern Language Journal, 84(2), 251-255.

Trang, T. T. T., Baldauf Jr., R. B. \& Moni, K. (2013). Investigating the development of foreign language anxiety: An autobiographical approach. Journal of Multilingual and Multicultural Development, 34(7), 709-726.

Wei, J. (2013). A study via interviews of the Chinese Bouyei College learners' EFL classroom anxiety coping strategies. Theory and Practice in Language Studies, 3(4), 660-668.

Yan, X., \& Horwitz, E. K. (2008). Learners' perceptions of how anxiety interacts with personal and instructional factors to influence their achievement in English: A qualitative analysis of EFL learners in China. Language Learning, 58(1), 151-183.

Zhang, R., \& Zhong, J. (2012). The hindrance of doubt: Causes of language anxiety. International Journal of English Linguistics. 2(3), 27-33. 